\title{
CRISES FALCIFORMES
}

\author{
SICKLE CELL CRISIS
}

Ivan de Lucena Ângulo

Médico. Centro Regional de Hemoterapia do Hospital das Clínicas da Faculdade de Medicina de Ribeirão Preto.

Correspondência: Rua Tenente Catão Roxo, 2501 - CEP 14051-140 Ribeirão Preto - SP. angulo@pegasus.fmrp.usp.br

ÂNGULO IL. Crises falciformes. Medicina, Ribeirão Preto, 36: 427-430, abr./dez. 2003.

RESUMO - Foi feita a revisão das complicações agudas da doença falciforme, ou crises, com sugestões de condutas, baseadas na literatura.

UNITERMOS - Anemia Falciforme. Anemia Hemolítica.

\section{1- CRISES DOLOROSAS}

Os episódios de vasoclusão são característicos das Doenças Falciformes, gerando dor isquêmica, de intensidade variável, geralmente, intensas, com recorrências imprevisíveis, que podem iniciar-se aos 6 meses de idade e durar a vida toda.

São responsáveis pela maioria dos casos de atendimentos de emergência e hospitalização, assim como pela má qualidade de vida dos pacientes acometidos. Internações freqüentes resultam em elevada mortalidade. O controle domiciliar dos episódios mais leves é possível, mas necessita de condições psicossociais, favoráveis, na família, o que é, geralmente, difícil ${ }^{(1)}$.

A dor, entretanto, faz parte de muitas manifestações da Doença Falciforme, podendo ser aguda ou crônica. Os episódios agudos, com grande participação dolorosa, são a síndrome toráxica aguda (STA), colecistite, síndrome mão-pé, priapismo, síndrome do hipocôndrio direito, seqüestro esplênico e crise vasoclusiva (CVO). A dor crônica é devida a artrite, artropatia, necrose asséptica, úlceras de perna, colapso de corpos vertebrais e síndromes neuropáticas. No entanto, freqüentemente, os episódios dolorosos são mistos, assim como as complicações citadas podem estar superpostas.
As características da dor aguda, ou da crise vasoclusiva, são de início súbito, sem explicação, intensidade variável (leve a intensa), duração de horas ou dias, caráter persistente ou recorrente e migração de um local para outro do corpo. Pacientes com crises frequientes são candidatos ao uso de hidroxiuréia ${ }^{(2)}$.

Já o que caracteriza a dor crônica é durar de 3 a 6 meses ou mais, e causar debilitação física e mental.

A abordagem do paciente com dor deve começar pela história e exame físico, nos quais se procura o fator desencadeante ou associado. Considera-se uma emergência médica, se houver a presença de dor abdominal intensa, vômitos recorrentes, sintomas respiratórios, paresias ou paralisias, artrite aguda, priapismo e anemia intensa ${ }^{(3)}$.

O tratamento médico da crise dolorosa, moderada ou intensa, deve incluir opióides com ou sem AINE associado. A morfina é a droga ideal para dor intensa, e a codeína é útil na moderada. A dependência física, a perda da eficácia analgésica e a dependência psicológica, ou adição, podem ocorrer com o uso crônico. A suspensão da droga deve ser gradual, para evitar a síndrome de abstinência. Os efeitos colaterais dos opióides são: depressão respiratória, náuseas e vômitos, prurido, alergia e constipação intestinal. A mepe- 
ridina não deve ser utilizada em pacientes com Doença Falciforme, por causa do efeito tóxico ao sistema nervoso central do metabolito normeperidina, que pode causar sintomas, como disforia, comportamento irritável, clônus e convulsões. Os analgésicos são a base do tratamento das crises dolorosas, porém a resposta do paciente é individual. Não se devem utilizar sedativos e ansiolíticos para controlar a dor, mas podem ser necessários para controlar a ansiedade e promover a sedação $0^{(3)}$.

Podemos classificar as crises dolorosas, agudas em leves/moderadas e graves. A crise de dor leve/ moderada pode ser controlada, inicialmente, com acetaminofen ou AINE e, não havendo melhora, devese usar a morfina oral ou o opióide codeína, sendo que leve sedação pode ser um efeito colateral até que desejável. Se houver associação de estado gripal ou virose com febre, tudo isso pode ser controlado com o uso de acetaminofen ou AINE. Pacientes com doença hepática não devem receber o acetaminofen. AINEs são contra-indicados em crianças abaixo de 6 anos de idade $^{(4)} \mathrm{e}$, em casos de gastrite, úlcera péptica, coagulopatias e insuficiência renal, sendo que usuários crônicos devem controlar a função renal a cada 3 a 6 meses $^{(3)}$. A aspirina não deve ser utilizada em crianças, pelo risco de causar a síndrome de Reye ${ }^{(4)}$.

A hidratação do paciente é considerada fator secundário no manejo da crise, e sugere-se a conduta preconizada na referência ${ }^{(1)}$. Transfusões de sangue são contra-indicadas nos episódios dolorosos sem complicações. Alguns pacientes sofrem de crises freqüentes e intensas, com deterioração da qualidade de vida, e podem beneficiar-se de transfusões crônicas, se não houver resposta ou não for possível utilizar hidroxiuréia ${ }^{(2,3)}$.

\section{2- CRISE APLÁSTICA}

O valor basal da hemoglobina $(\mathrm{Hb})$, no paciente com doença falciforme, resulta do equilíbrio entre produção e destruição, equilíbrio que pode ser rompido em várias situações, como as mencionadas a seguir.

- Agudamente, por sangramentos, infecção pelo Parvovírus (crise aplástica), seqüestro esplênico ou hepático, hemólise por deficiência de glicose-6fosfato-dehidrogenas (G6PD), infecção por Mycoplasma ou Malária. Manifesta-se por dispnéia, hipotensão, cansaço acentuado ou insuficiência cardíaca, congestiva, com $\mathrm{Hb}<5 \mathrm{~g} / \mathrm{dl}$, podendo ocorrer morte súbita por colapso cardiovascular.

- Cronicamente, por insuficiência renal crônica (IRC).
A crise aplástica manifesta-se por anemia e reticulocitopenia $<1 \%$, sendo, muitas vezes, causada por infecção pelo Parvovírus B19, sem o rash cutâneo, característico. Pode estar associada a CVO intensa, necrose da medula óssea, STA, seqüestro esplênico e AVC. O Parvovírus é contagioso e coloca em risco o pessoal da saúde, sendo que as grávidas devem ser afastadas, assim como outros pacientes com imunodeficiência e anemia hemolítica, assim como os irmãos do paciente, também acometidos de Doença Falciforme. As transfusões simples são indicadas, quando houver redução brusca dos valores basais da hemoglobina do paciente ou insuficiência crônica de órgãos. Deve-se transfundir para conservar a $\mathrm{Hb} \mathrm{A}$ em $50 \%$ a $70 \%$, suprimindo a produção de $\mathrm{Hb} \mathrm{S}$. O valor do hematócrito pós-transfusional não deve ultrapassar 36\%, devido ao risco de causar hiperviscosidade e alteração do fluxo cerebral ${ }^{(5)}$.

\section{3- CRISE DE SEQÜESTRO ESPLÊNICO}

Caracterizado por esplenomegalia, dolorosa, maciça, em crianças (baço 4-10 cm), acompanhado de anemia, com queda da $\mathrm{Hb}$ de $2 \mathrm{~g} / \mathrm{dl}$ abaixo do valor basal, plaquetopenia $<100.000 \mu \mathrm{l}$ e reticulocitose. Pode caminhar rapidamente para o choque hipovolêmico e morte, sendo, portanto, uma emergência transfusional, devendo ser tratada com transfusão rápida de eritrócitos 10-20 ml/kg em uma hora. Após a transfusão, há a possibilidade de ocorrer o fenômeno de overshoot, ou seja, hiperviscosidade por grande elevação do Ht, por causa da liberação dos eritrócitos seqüestrados. Em paciente estável, pode-se transfundir concentrado de eritrócitos $5 \mathrm{ml} / \mathrm{kg}$ em 2 a $3 \mathrm{~h}$ e, depois, passar a transfusões de manutenção a $5-10 \mathrm{ml} /$ $\mathrm{kg}$. A recorrência da crise é em torno de $50 \%$, podendo ocorrer, inclusive, em adultos com hemoglobinopatia $\mathrm{SC}$, e o tratamento definitivo é esplenectomia. Devese suspeitar de seqüestro crônico, se houver esplenomegalia de 3-6 cm, leve anemia e plaquetopenia e queda da $\mathrm{Hb}$ após infecções. O paciente deve ser vacinado antes e mantido em profilaxia penicilínica a vida toda, após a cirurgia ${ }^{(5)}$.

\section{4- CRISE NEUROLÓgICA}

O acidente vascular cerebral (AVC) acomete $5 \%$ dos pacientes, principalmente, anemia falciforme (Hb SS), e tem elevado índice de recorrência (67\%). Ocorre em crianças, por oclusão arterial, intracraniana, 
e, nos adultos, por trombose ou hemorragia. Os fatores de risco são presença de leucocitose, anemia grave, crise vasoclusiva (CVO), síndrome torácica aguda, AVC anterior e hipertensão arterial. A clínica, nos casos clássicos, nem sempre presente, manifesta-se com sinais neurológicos focais, hemiplegia, hemiparesia, afasia, convulsões e coma. Podem aparecer, também, cefaléia de forte intensidade, alterações visuais e perda breve da consciência. O paciente deve ser hidratado, submetido a avaliação neurológica, completa e submetido a transfusão de troca, a fim de reduzir a concentração de $\mathrm{Hb} \mathrm{S}<30 \%$,dentro de 6-12 h após a internação. Após a fase aguda, o paciente será mantido em transfusões crônicas $10-20 \mathrm{ml} / \mathrm{kg}$ a cada 3 a 4 semanas com o objetivo de manter $\mathrm{Hb}$ alvo de 9-12 g/ $\mathrm{dl}$, em crianças, e 8-10 g/dl, em adultos, mantendo os níveis de $\mathrm{Hb} \mathrm{S}<30 \%$. Tal abordagem tem custo elevado e complicações, como aloimunização, transmissão de doenças infecciosas e hemocromatose. As alternativas para a redução dessas complicações são: aumentar o intervalo transfusional, utilizar eritrocitaférese, uso de hidroxiuréia e transplante de medula óssea ${ }^{(3)}$.

Transfusão de troca: permite a substituição rápida de $\mathrm{Hb} \mathrm{S}$ por $\mathrm{Hb} \mathrm{A}$, sem aumentar a viscosidade ou a sobrecarga de ferro. As indicações são AVC, síndrome toráxica, aguda, lesão de múltiplos órgãos, oclusão de artérias retinianas e no pré-operatório. Técnica: com o objetivo de atingir hematócrito (Ht) de $30 \%$ (Hb 10 a 12 g/dl) em adultos e $\mathrm{Hb} \mathrm{S}<30 \%$, inicia-se com uma sangria de $500 \mathrm{ml}+$ infusão de 500 $\mathrm{ml}$ de salina, nova sangria de $500 \mathrm{ml}$ e transfusão de 2 unidades de concentrado de eritrócitos. Deve ser repetido por uma ou duas vezes. Ou, então, efetuar sangrias e transfusões de $500 \mathrm{ml}$ por 6 a 8 ciclos, utilizando 6 a 8 unidades, em adultos, e $50-60 \mathrm{ml} / \mathrm{kg}$, em crianças. A eritrocitaférese é segura e reduz o risco de hemocromatose, porém, tem limitações como o custo elevado, acesso venoso e aumento da exposição a múltiplos doadores ${ }^{(1)}$.

\section{5- SÍNDROME TORÁCICA AGUDA}

Acomete 15 a $43 \%$ dos pacientes, com recorrências causadoras de fibrose pulmonar e mortalidade elevada em adultos, particularmente no pós-operatório. Causas: infecciosa, em crianças, complexa, em adultos (virose, pneumonites, embolia gordurosa e infartos pulmonares). Pode manifestar-se agudamente ou após 2 a 3 dias de CVO intensa, assim como complicação de cirurgia e anestesia geral. Pode evo- luir rapidamente para falência respiratória e morte. Clínica: dor toráxica, com ou sem febre, hipoxemia, leucocitose e lesões radiológicas, móveis. Tratamento: suporte respiratório, oxigênio, antibióticos e transfusão. Casos com anemia e hipoxemia leves, transfusões simples de concentrado de eritrócitos. Se mais graves, efetuar transfusão de troca mantendo $\mathrm{Hb} \mathrm{S}$ e Ht final $<30 \%$, devendo ocorrer melhora clínica e radiológica em 24 horas $^{(3)}$.

\section{6- PRIAPISMO}

Ereção dolorosa, permanente e não desejada, do pênis é comum em crianças e adolescentes ou adultos jovens e manifesta-se nas primeiras horas da manhã, com risco de causar impotência sexual. Há obstrução da drenagem venosa do pênis. São definidas duas formas clínicas: o priapismo agudo (PA), caracterizado por duração prolongada (mais de $3 \mathrm{~h}$ ), e que pode levar à impotência, e o priapismo intermitente crônico (PIC), caracterizado por crises repetidas, mas de curta duração (menos de $3 \mathrm{~h}$ ), e que pode evoluir para priapismo agudo. O PA prolongado (mais de 24-48 h) pode acarretar disfunção erétil permanente. Por isso, é importante a adoção de medidas terapêuticas imediatamente após o diagnóstico, que tem por objetivo reverter o PA, idealmente em menos de $24 \mathrm{~h}$. Os pacientes devem ser orientados a procurar atendimento médico, se o priapismo tiver duração de mais de $3 \mathrm{~h}$, ou mesmo antes, se houver dor. O tratamento do PA deve ser feito em etapas, iniciando com hidratação vigorosa, com salina $0,9 \%$, analgesia (morfina ou outro opióide), ansiolítico (midazolan) em pacientes mais ansiosos, oxigenoterapia, se a saturação for menor que $88 \%$, e agonista $\alpha$-adrenérgico (pseudoefedrina 30$60 \mathrm{mg}$, via oral). Sem melhora significativa, em 2 a $3 \mathrm{~h}$, com as medidas iniciais, inicia-se aspiração e irrigação dos corpos cavernosos e, eventualmente, transfusões de sangue. $O$ tratamento do PIC é controverso e existem vários protocolos ${ }^{(3,6,7)}$. A prevenção pode ser obtida, em alguns pacientes, com hidroxiuréia.

\section{7- LESÕES ORGÂNICAS AGUDAS}

Vários órgãos podem ser acometidos (pulmões, fígado, rins, medula óssea) isolados ou concomitantes (síndrome da falência de múltiplos órgãos), sendo a causa a hiperviscosidade ou valores elevados do $\mathrm{Ht}$, como pode ocorrer na hemoglobinopatia SC. O tratamento, emergencial, é transfusão de troca por eritrocitaférese, com sangria prévia, mantendo $\mathrm{Hb} \mathrm{A}>$ 
$80 \%$ e $\mathrm{Ht}<28 \%$. A mortalidade é elevada $(25 \%$ dos casos) e a manutenção deve ser efetuada com transfusões simples ${ }^{(5)}$.

\section{8- CRISE HEMOLÍTICA E COMPLICAÇÕES DE TRANSFUSÕES DE SANGUE}

A maioria dos pacientes é transfundida em algum momento da vida (60\% aos 20 anos de idade), havendo tendência de se formarem múltiplos anticorpos. Mesmo com a possibilidade de $30 \%$ deles desaparecerem, poderão acontecer reações anamnésticas a transfusões futuras, causando reações transfusionais, hemolíticas, tardias, 05 a 20 dias após, por anticorpos indetectados no pré-transfusional, que poderão ocasionar piora da anemia, CVO e morte. Haverá dificuldade em se encontrar sangue compatível ${ }^{(5)}$. Em alguns pacientes altamente aloimunizados, poder-seão encontrar manifestações de auto-imunidade, tais como Coombs direto, positivo, tornado-se o paciente mais anêmico que antes da transfusão. É a síndrome de hiper-hemólise falciforme e pode ser de extrema gravidade. Anticorpos contra antígenos próprios podem durar 2 a 3 meses, e o tratamento poderá ser feito com corticóides, altas doses de eritropoietina (EPO) e imunoglobulina intravenosa ${ }^{(8)}$.

Anticorpos contra leucócitos, plaquetas ou proteínas podem causar reações febris ou alérgicas, que poderão ser prevenidas por desleucotização por lavagem, filtração, uso de anti-histamínicos e remoção do plasma.

\section{9- INFECÇÕES}

O episódio febril, no paciente com doença falciforme, deve ser interpretado como sendo em paciente, sem a função protetora do baço (asplenia funcional) e avaliado rapidamente (exame clínico, hemograma, radiografia de tórax e culturas de urina e sangue), pois há, latente, o risco de morte por septicemia pelo estreptococo. A temperatura corporal acima de $38,5^{0} \mathrm{C}$ e sem sinais de localização da infecção, deve ser considerada emergência médica, e o paciente internado. Porém, acima de $40^{\circ} \mathrm{C}$, e paciente com aspecto tóxico (mau estado geral), deve-se usar antibioticoterpia empírica, endovenosa, antes mesmo da coleta de material para os testes laboratoriais. Há vários protocolos de utilização de antibióticos ${ }^{(3,4)}$.

ANGULO IL. Sickle cell crisis. Medicina, Ribeirão Preto, 36: 427-430, apr./dec. 2003.

ABSTRACT - A review of acute events or crisis in sickle cell disease was made with suggestions of clinical skills based on literature.

UNITERMS - Anemia, Sickle Cell. Anemia, Hemolytic.

\section{REFERÊNCIAS BIBLIOGRÁFICAS}

1 - REES DC; OLUJOHUNGBE AD; PARKER NE; STEPHENS AD; TELFER P \& WRIGHT J. Guidelines for the management of the acute painful crisis in sickle cell disease. $\mathbf{B r} \mathbf{J}$ Haematol 120:744-752, 2003.

2 - CHARACHE S; TERRIN ML; MOORE RD; DOVER GJ; BARTON FB; ECKERT SV; MCMAHON RP \& BONDS DR. Effect of hydroxyurea on the frequency of painful crises in sickle cell anemia. Investigators of the Multicenter Study of Hydroxyurea in Sickle Cell Anemia. N Engl J Med 332 (20): 1317-1322, 1995.

3 - NATIONAL INSTITUTES OF HEALTH, NATIONAL HEART, LUNG, AND BLOOD INSTITUTE. DIVISION OF BLOOD DISEASES AND RESEARCH. The Management of Sickle Cell Disease. NIH Publication No. 02-2117, june 2002. Disponível em www.nhlbi.nih.gov/health/prof/blood/sickle/index.htm.
4 - AMERICAN ACADEMY OF PEDIATRICS. Section on Hematology/Oncology. Comitee on Genetics. Health Supervision for Children with Sickle Cell Disease. Pediatrics 109: 526-534, 2002.

5 - ROSSE WF; TELEN M \& WARE R. Transfusion support for patients with sickle cell disease. AABB Press, Bethesda, Maryland, 1998.

6 - BRUNO D; WIGFALL DR; ZIMMERMAN AS; ROSOFF PM \& WIENER JS. Genitourinary complications of sickle cell disease. J Urol 166: 803-811, 2001.

7 - HAKIM LS; HASHMAT AI \& MACCHIA RJ: Priapism. In: EMBURY SH; HEBBEL RP; MOHANDAS N \& STEINBERG MH, eds. Sickle cell disease: Basic principles and clinical practice. Raven Press, New York, p. 633-643, 1994.

8 - PETZLD; CALHOUM L; SHULMAN IA; JOHNSON C \& HERRON $\mathrm{RM}$ : The sickle cell hemolytic reaction syndrome. Transfusion 37: 382-392, 1997. 